\title{
Role of Steroids in Hyperexcitatory Adverse and Anesthetic Effects of Sevoflurane in Neonatal Rats
}

\author{
Jiaqiang Zhang ${ }^{\mathrm{a}, \mathrm{c}}$ Changqing $\mathrm{Xu}^{\mathrm{a}}$ Dyanet L. Puentes ${ }^{\mathrm{a}}$ Christoph N. Seubert ${ }^{\mathrm{a}}$ \\ Nikolaus Gravenstein ${ }^{a, b}$ Anatoly E. Martynyuk ${ }^{a, b}$ \\ ${ }^{a}$ Department of Anesthesiology, and ${ }^{b}$ McKnight Brain Institute, University of Florida College of Medicine, \\ Gainesville, Fla., USA; 'Department of Anesthesiology, People's Hospital of Zhengzhou University, \\ Zhengzhou, PR China
}

\section{Key Words}

Steroids $\cdot$ Seizures $\cdot$ Sevoflurane $\cdot$ Neonatal anesthesia .

Estradiol

\begin{abstract}
Recent studies have demonstrated that long-term developmental effects of neonatal anesthesia were more prominent in males. We tested whether steroids, in general, and sex steroids, in particular, are involved in the mediation of sevoflurane-caused paradoxical cortical seizures during the early postnatal period. Methods: Cortical electroencephalograms, hippocampal synaptic activity, serum levels of steroids and the loss of the righting reflex (LORR), a marker of anesthetic effect, were measured on postnatal days 4-6 in Sprague Dawley rats of both genders exposed to $2.1 \%$ sevoflurane. Results: Episodes of seizures, persistent spikes in electroencephalograms and increases in serum corticosterone were similar in both genders. In the order of increasing potency, the corticosteroid receptor antagonist RU 28318, the estradiol receptor antagonist ICI 182780 and the estradiol synthesis inhibitor formestane decreased sevoflurane-induced seizures. Exogenous estradiol increased sevoflurane-caused seizures, spikes and serum levels of corticosterone. These estradiol-enhanced seizures and spikes were depressed by
\end{abstract}

ICI 182780 and the NKCC1 inhibitor, bumetanide, while RU 28318 decreased seizures only. In hippocampal CA1 neurons, estradiol increased the amplitude, rise time and area under the curve of gamma-aminobutyric acid type $A$ receptor $\left(\mathrm{GABA}_{\mathrm{A}} \mathrm{R}\right)$-mediated miniature postsynaptic currents. Exogenous estradiol shortened, while ICI 182780 and formestane lengthened the time needed for sevoflurane to induce LORR. Conclusion: These findings provide evidence for gender-independent acute electroencephalographic effects of sevoflurane at this age. Corticosterone and estradiol are involved in the mediation of sevoflurane-induced seizures. Estradiol, but not corticosterone, also contributes to sevoflurane-caused spikes, by enhancing $G A B A_{A} R$-mediated excitation in the cortex. By increasing $G A B A_{A} R$-mediated inhibition in more mature caudal regions of the brain, estradiol contributes to sevoflurane-induced LORR.

๑) 2015 S. Karger AG, Basel

\section{Introduction}

Our recent experimental findings demonstrated that exposure of neonatal rats to propofol caused multifold increases in the secretion of the corticosteroid hormones corticosterone and aldosterone at the time of anesthesia

\section{KARGER}

E-Mail karger@karger.com

www.karger.com/nen (c) 2015 S. Karger AG, Basel

0028-3835/15/1035-0440\$39.50/0
Anatoly E. Martynyuk

Department of Anesthesiology, University of Florida PO Box 100254, JHMHC

1600 SW Archer Road, Gainesville, FL 32610-0254 (USA)

E-Mail AMartynyuk@anest.ufl.edu 
Fig. 1. Illustration of the experimental protocols involving the investigation of the electroencephalographic effects of sevoflurane.

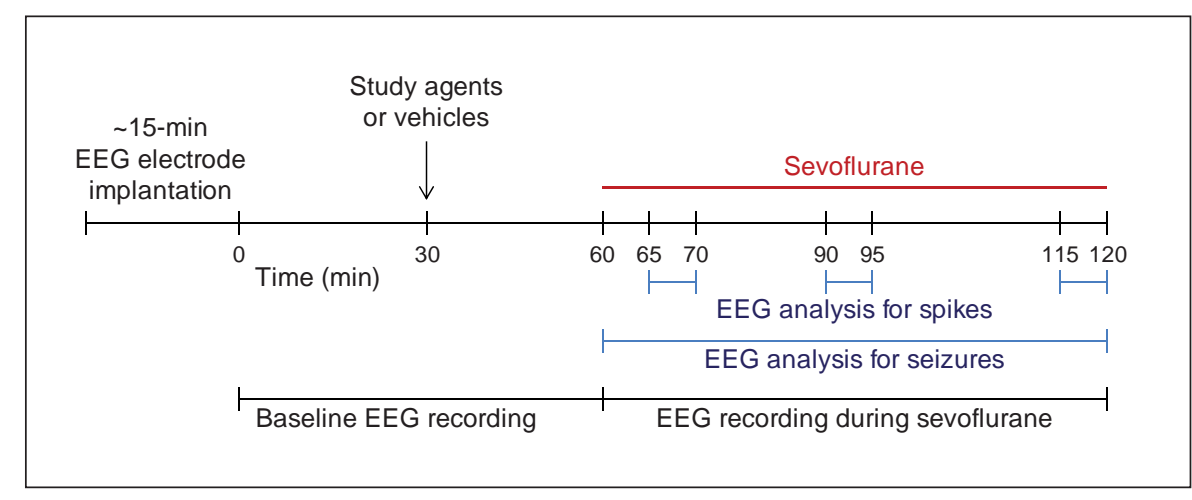

in both genders, while long-term impairment in sensorimotor gating function (reduction in the prepulse inhibition of the startle response) was observed in male, but not female, adult rats exposed to propofol as neonatal rats $[1,2]$. Greater susceptibility of male rats to developmental effects of neonatal anesthesia with isoflurane and phenobarbital were reported by other laboratories $[3,4]$. Interestingly, Lee et al. [4] found that isoflurane, when administered to postnatal day $(\mathrm{P}) 7$ rats, acutely caused neuronal death in both genders, but long-term developmental effects of isoflurane, such as impaired object recognition and impaired social memory, were evident in male rats only. The existence of a gender dependence suggests ways to focus on the search for a mechanistic explanation of the developmental effects of neonatal anesthesia.

Steroids, in general, and sex steroids, in particular, such as estrogen and estradiol, seem to be plausible mediators of such developmental effects. Estradiol is at its highest levels during the perinatal period; its levels in the cortex are similar in male and female rats, but its levels in the hypothalamus are higher in male than female rats at this age $[5,6]$. Estradiol positively modulates corticosterone levels and gamma-aminobutyric acid (GABA)ergic transmission [7-11]. Available data suggest that GABA type A receptor $\left(\mathrm{GABA}_{\mathrm{A}} \mathrm{R}\right)$-mediated excitation and elevated systemic corticosterone levels at the time of anesthesia may contribute to the mechanisms that not only initiate the long-term adverse developmental effects of propofol, but also underlie propofol-caused acute electroencephalographic seizures $[1,2]$. Consequently, probing the mechanisms of anesthetic-caused electroencephalographic cortical seizures may provide a key to understanding the mechanisms underlying long-term developmental abnormalities induced by anesthesia in neonates.

With this in mind, we investigated the paradoxical acute hyperexcitatory electroencephalographic effects of sevoflurane in $\mathrm{P} 4,5$ or 6 male and female rats and the roles of steroids, with a particular focus on estradiol, in mediating these effects.

\section{Materials and Methods}

\section{Animals}

P4-6 Sprague Dawley rats of both genders were studied. All experimental procedures were approved by the University of Florida Institutional Animal Care and Use Committee. Pups from several litters were used for each treatment condition. At the beginning of each experiment, the pups were determined to be well nourished as judged by their stomachs being full of milk (detectable through the transparent abdominal wall).

\section{Study Design and Anesthesia Regimen}

All studies using electroencephalography (EEG) involved a single 60-min general anesthetic exposure to sevoflurane (fig. 1). Electroencephalographic recordings started after recovering from anesthesia for electrode implantation and lasted for $1 \mathrm{~h}$ before initiation of anesthesia with sevoflurane (baseline) and continued for another hour during anesthesia with sevoflurane $-6 \%$ sevoflurane for $3 \mathrm{~min}$ for anesthesia induction and $2.1 \%$ sevoflurane for $57 \mathrm{~min}$ for anesthesia maintenance. Electroencephalogram recordings were performed in a thermostated chamber $\left(+37^{\circ} \mathrm{C}\right)$ with a continuous supply of oxygen ( 1.5 liters/min). Anesthesia gas monitoring was performed using a calibrated Datex side stream analyzer (Datex-Ohmeda, Helsinki, Finland), which sampled from the interior of the animal chamber. According to Orliaguet et al. [12], $2.1 \%$ sevoflurane lies near the 0.6 minimum alveolar concentration for P4-P6 rats. Using the chamber-equilibrated dose of $2.1 \%$ sevoflurane, the pups did not exhibit a righting reflex. Previously, we had shown that blood glucose and gas levels after $1 \mathrm{~h}$ of anesthesia with $2.1 \%$ sevoflurane were in the normal range [13]. All animals were without cyanosis and breathing regularly during anesthesia exposure. A rectal temperature probe was placed in some animals to monitor body temperature.

Treatments or vehicles were administered 30 min prior to anesthesia with sevoflurane to $\mathrm{P} 4-\mathrm{P} 6$ rat pups. The following treatment groups were investigated: (1) vehicle prior to anesthesia with sevoflurane to male pups ( $\mathrm{n}=10)$; (2) vehicle prior to anesthesia 
with sevoflurane to female pups $(n=11)$; (3) the estrogen receptor agonist $\beta$-estradiol (estradiol; $0.1 \mathrm{mg} / \mathrm{kg}$, s.c.) prior to anesthesia with sevoflurane to male pups $(\mathrm{n}=8)$; (4) estradiol $(0.1 \mathrm{mg} / \mathrm{kg}$, s.c.) prior to anesthesia with sevoflurane to female pups $(n=7)$; (5) the mineralocorticoid receptor antagonist RU 28318 (10 mg/kg, i.p., $\mathrm{n}=9)$; (6) the estradiol receptor antagonist ICI $182780(0.05 \mathrm{mg} /$ $\mathrm{kg}$, s.c., $\mathrm{n}=11)$; (7) the estradiol synthesis inhibitor formestane $(2 \mathrm{mg} / \mathrm{kg}$, s.c., $\mathrm{n}=10)$; (8) estradiol $(0.1 \mathrm{mg} / \mathrm{kg}$, s.c.) plus the NKCC1 inhibitor bumetanide (1.82 mg/kg, i.p., $\mathrm{n}=8)$; (9) estradiol (0.1 mg/kg, s.c.) plus ICI 182780 (0.05 mg/kg, s.c., $\mathrm{n}=6)$; (10) estradiol (0.1 mg/kg, s.c.) plus RU $28318(10 \mathrm{mg} / \mathrm{kg}$, i.p., $\mathrm{n}=8)$.

All study agents were dissolved in DMSO, except bumetanide, which was dissolved in saline. Therefore, equal volumes of DMSO or saline were used as vehicle. DMSO at these volumes does not cause any detectable effects on hyperexcitatory EEG effects of anesthetics in neonatal rats [2].

To assess serum levels of corticosterone and estradiol in conditions identical to those used to study the electroencephalographic effects of sevoflurane, separate groups of P4-P6 rat pups underwent surgery for electrode implantation and 1-hour separation from their dams before initiation of anesthesia with sevoflurane for $1 \mathrm{~h}$. Treatments or vehicles were administered $30 \mathrm{~min}$ prior to anesthesia with sevoflurane. Blood samples were collected at $1 \mathrm{~h}$ of anesthesia with sevoflurane. The following treatment groups were investigated: (1) vehicle, no anesthesia $(n=6) ;(2)$ vehicle prior to anesthesia with sevoflurane ( $\mathrm{n}=4)$; (3) ICI $182780(0.05 \mathrm{mg} / \mathrm{kg}$, s.c.) prior to anesthesia with sevoflurane $(n=4)$; $(4)$ estradiol $(0.1$ $\mathrm{mg} / \mathrm{kg}$, s.c.) prior to anesthesia with sevoflurane $(\mathrm{n}=5)$.

To test whether estradiol may enhance the hyperexcitatory electroencephalographic effects of sevoflurane by enhancing $\mathrm{GABA}_{\mathrm{A}} \mathrm{R}$ activity, the effects of estradiol on $\mathrm{GABA}_{\mathrm{A}} \mathrm{R}$-mediated miniature postsynaptic currents (mPSCs) in P4-P6 hippocampal CA1 pyramidal neurons were studied $(n=7)$. To test whether the estradiol receptors mediate estradiol-caused enhancement of $\mathrm{GABA}_{\mathrm{A}} \mathrm{R}$ activity, the effects of the estradiol receptor antagonist ICI 182780 on estradiol-enhanced $\mathrm{GABA}_{\mathrm{A}} \mathrm{R}$-mediated mPSCs were evaluated $(\mathrm{n}=3)$.

To obtain additional indirect evidence that estradiol may enhance the hyperexcitatory electroencephalographic effects of sevoflurane by enhancing $\mathrm{GABA}_{\mathrm{A}} \mathrm{R}$ activity, the role of estradiol in sevoflurane-caused loss of the righting reflex (LORR) was studied in $\mathrm{P} 4-\mathrm{P} 6$ rat pups. The righting reflex is predominantly mediated by midbrain neuronal networks as evident from its preservation in decerebrate rodents $[14,15]$. If estradiol enhances the hyperexcitatory cortical electroencephalographic effects of sevoflurane by enhancing $\mathrm{GABA}_{\mathrm{A}} \mathrm{R}$-mediated excitation, then estradiol should promote sevoflurane-caused LORR by enhancing $\mathrm{GABA}_{\mathrm{A}} \mathrm{R}$-mediated inhibition in the midbrain structures of $\mathrm{P} 4-\mathrm{P} 6$ rat pups. In order to measure the latency to LORR, a rat pup was placed in a thermostated chamber filled with 3.5\% sevoflurane. Sevoflurane supply to the chamber and measurement of sevoflurane levels in the chamber were performed as described above. The vehicle or treatments were administered $30 \mathrm{~min}$ prior to the placement of the rat into the chamber filled with sevoflurane. 3.5\% sevoflurane lies near the 1 minimum alveolar concentration for P4-P6 rats [12]. We chose to use 3.5\% sevoflurane for the LORR studies, because with sevoflurane concentrations of 6 and $2.1 \%$ that we used for the induction and maintenance of anesthesia in the electroencephalographic studies, LORR was too fast and too slow, respectively.

The following treatment groups were investigated: (1) vehicle prior to anesthesia with sevoflurane $(\mathrm{n}=5) ;(2)$ estradiol $(0.1 \mathrm{mg} /$ $\mathrm{kg}$, s.c.) prior to anesthesia with sevoflurane $(\mathrm{n}=5)$; (3) ICI 182780 $(0.05 \mathrm{mg} / \mathrm{kg}$, s.c.) prior to anesthesia with sevoflurane $(\mathrm{n}=6)$; (4) formestane ( $2 \mathrm{mg} / \mathrm{kg}$, s.c.) prior to anesthesia with sevoflurane $(\mathrm{n}=5)$.

\section{Electroencephalogram Recordings}

Electroencephalogram recordings were performed in a thermostated chamber $\left(+37^{\circ} \mathrm{C}\right)$ with a continuous supply of oxygen (1.5 liters/min).

To study cortical electrical activity in P4-P6 rat pups, animals were instrumented for electroencephalogram recording as described previously $[2,13,16]$. In brief, during a 12 - to 15 -min minor surgical procedure performed under isoflurane anesthesia (1.6-2.0\%), 4 electrodes were implanted in bilateral occipital and frontal regions of the rat pup skull with the left frontal electrode serving as the reference electrode. Electroencephalogram recordings were performed using an electroencephalogram/electromyogram system (Pinnacle Technology, Lawrence, Kans., USA). Acquisition of the electroencephalogram was performed using the Sirenia software (Pinnacle Technology). The sampling interval per signal was $200 \mu \mathrm{s}(5 \mathrm{kHz})$. Sirenia Score (Pinnacle Technology), Clampfit 9.2 (Axon Instruments, Union City, Calif., USA) and MiniAnalysis (Synaptosoft Inc., Fort Lee, N.J., USA ) programs were used for the electroencephalogram data analysis. Data were filtered offline using a bandpass Bessel (8-pole) 0.04- to 56-Hz filter. Root mean square of the electroencephalogram was computed for 2.56-second segments.

All EEG studies involved a single 60-min general anesthetic exposure to sevoflurane (fig. 1).

We have previously verified that no obvious differences in electroencephalographic activity were detected when electroencephalogram electrode implantation was done either immediately prior or 1-2 days before the start of electroencephalogram recording [17].

Electroencephalogram patterns characterized by an amplitude of at least three times higher than baseline and rhythmic $(>2 \mathrm{~Hz})$ activity that lasted for at least $3 \mathrm{~s}$ and abruptly reverted to baseline were defined as seizure-like electroencephalogram patterns. In most cases, these patterns started as high frequency-low amplitude activity that developed to increased amplitude and decreased frequency and then abruptly reverted to baseline activity. All parameters for EEG seizures, such as the total duration, number of episodes, and average episode duration, were calculated for the entire 60 -min period of sevoflurane exposure (fig. 1). For example, the average episode duration of EEG seizures was calculated as the total duration of EEG seizures during 60 min of anesthesia with sevoflurane divided by the number of episodes of EEG seizures during 60 min of anesthesia with sevoflurane. Continuous isolated spikes that appeared in electroencephalograms recorded in anesthetized rat pups were not considered as EEG seizures and were analyzed separately. The EEG spike activity during $60 \mathrm{~min}$ of exposure to sevoflurane was analyzed during three 5-min periods: (1) early during sevoflurane exposure (5-10 min of anesthesia); (2) in the middle of sevoflurane exposure (30-35 min of anesthesia with sevoflurane), and (3) at the end of exposure (55-60 min of exposure to sevoflurane) (fig. 1). The investigators analyzing the EEGs were blinded to the experimental conditions, and all EEGs were reviewed by 3 independent reviewers. About 5\% of animals exhibited episode(s) of seizure-like electroencephalogram patterns before the start of anesthesia and were not included in the data anal- 
ysis. Histopathological analysis linked most of these seizures to brain injuries during surgery for the EEG electrode implantation.

\section{Measurement of Serum Corticosterone and Estradiol}

Serum corticosterone and estradiol were measured using commercial ELISA kits (Cayman Chemical Company, Ann Arbor, Mich., USA) following the manufacturer's instructions.

\section{Slice Electrophysiology}

Voltage clamp recordings of membrane ionic currents were conducted by using an Axopatch 200B amplifier (Axon Instruments Inc.) as previously described [1]. In brief, brain hippocampal slices were prepared from P4-P6 rats. The brain was removed after decapitation and was placed into ice-cold sucrose buffer containing (in millimoles): 254 sucrose, $10 \mathrm{D}$-glucose, $26 \mathrm{NaHCO}_{3}$, $2 \mathrm{CaCl}_{2}, 2 \mathrm{MgSO}_{4}, 3 \mathrm{KCl}$, and $1.25 \mathrm{NaH}_{2} \mathrm{PO}_{4}$, saturated with $95 \%$ $\mathrm{O}_{2} / 5 \% \mathrm{CO}_{2}$, at $\mathrm{pH}$ 7.4. Transverse hippocampal slices $(300 \mu \mathrm{m}$ thick) were cut with a VT $1000 \mathrm{~S}$ microtome (Leica Microsystems Inc., Buffalo Grove, Ill., USA). Slices were transferred immediately into a holding chamber and were incubated at $32-33^{\circ} \mathrm{C}$ for a 30 -min recovery period in a mixture of $50 \%$ sucrose saline and $50 \%$ artificial cerebrospinal fluid (aCSF) containing (in millimoles): $128 \mathrm{NaCl}, 10 \mathrm{D}$-glucose, $26 \mathrm{NaHCO}_{3}, 2 \mathrm{CaCl}_{2}, 2 \mathrm{MgSO}_{4}, 3 \mathrm{KCl}$, and $1.25 \mathrm{NaH}_{2} \mathrm{PO}_{4}$. Slices were then placed on a nylon mesh, submerged in normal aCSF bubbled continuously with 95\% $\mathrm{O}_{2} / 5 \%$ $\mathrm{CO}_{2}$, and maintained at room temperature $\left(\sim 21-24^{\circ} \mathrm{C}\right)$ until whole-cell patch clamp recording, typically within $0.5-5 \mathrm{~h}$.

The slices were transferred to a submersion-type recording chamber (Warner Instruments, Hamden, Conn., USA) on a Burleigh Gibraltar fixed-stage system (Burleigh Instruments, Fisher, N.Y., USA), secured beneath a nylon harp, and perfused with aCSF heated to $30-33^{\circ} \mathrm{C}$ with an inline heater (Warner SC-20) at a rate of $2-3 \mathrm{ml} / \mathrm{min}$. CA1 pyramidal cells were identified visually by using a microscope (Leica DM LFS, Leica Microsystems Wetzlar GmbH, Wetzlar, Germany) equipped with a $\times 40$ water immersion objective coupled with an infrared differential interference contrast camera system. Whole-cell patch clamp recordings were established using an Axopatch 200B amplifier (Axon Instruments). Membrane current and potential signals were digitized and analyzed with Digidata 1322A (Molecular Devices, Sunnyvale, Calif., USA) and pClamp 10.0 systems (Molecular Devices). Patch pipettes of approx. $5 \mathrm{M} \Omega$ were pulled with a P-1000 puller (Sutter Instruments, Novato, Calif., USA). The pipette solution had the following composition (in millimoles), unless stated otherwise: $140 \mathrm{KCl}, 0.1 \mathrm{CaCl}_{2}$, 5 EGTA, $10 \mathrm{HEPES}, 4 \mathrm{ATP}$ $\mathrm{Mg}^{2+}, 0.4 \mathrm{GTP}-2 \mathrm{Na}^{+}, 1$ QX314 (lidocaine N-ethyl bromide), $\mathrm{pH}$ 7.2 and $290 \mathrm{mOsm}$. The diffusion potential (liquid junction potential) was $4 \mathrm{mV}$, calculated by Clampex software (Molecular Devices). QX314 was added to the pipette solution to block the $\mathrm{GABA}_{\mathrm{B}} \mathrm{R}$-mediated currents and to prevent the generation of $\mathrm{Na}^{+}$-dependent action potentials. Under these conditions, mPSCs were acquired in aCSF containing tetrodotoxin $(1 \mu \mathrm{M})$ at a holding potential of $-70 \mathrm{mV}$. To record $\mathrm{GABA}_{\mathrm{A}} \mathrm{R}$-mediated mPSCs, glutamate receptor antagonists DNQX (6,7-dinitroquinoxaline-2,3-dione, $20 \mu \mathrm{M}$ ) and AP5 (DL-2-amino-5-phosphonovaleric acid, $20 \mu \mathrm{M}$ ) were added to aCSF. Drugs were administered by bath application. Estradiol $(1 \mu \mathrm{M})$ was given after $10 \mathrm{~min}$ of baseline recording, and application of picrotoxin $(100 \mu \mathrm{M})$ was initiated at $30 \mathrm{~min}$ from the start of the recording (20 min after initiation of estradiol application). Synaptic currents were collected for
5 min for each experimental condition. Access resistance $(<25$ $\mathrm{M} \Omega$ ) was regularly monitored during recordings, and cells were rejected if the resistance changed by $>15 \%$ during the experiment. If the access resistance increased during the course of the experiment and caused significant reductions in the synaptic current amplitudes, efforts were made to improve access (such as applying additional suction or a slight positive pressure); if this failed, the experiment was discontinued. Synaptic currents were filtered at $2 \mathrm{kHz}$ and were digitized at $10 \mathrm{kHz}$ using Digidata 1322A (Molecular Devices). Offline data analysis was performed using the MiniAnalysis software (version 6.0.7; Synaptosoft, Decatur, Ga., USA) by evaluating the last 3-min interval of each experimental condition. An amplitude threshold of $10 \mathrm{pA}$ was used for automatic detection. Events were then visually screened to eliminate false detections.

\section{Measurement of Latency to LORR}

The rat pup was placed in the anesthetic prefilled chamber, and the time during which the rat pup lost the response to slow rotating-like movements of the chamber was recorded with a stopwatch. This time was considered the time needed for sevoflurane to induce LORR.

\section{Drugs}

Sevoflurane was manufactured by Fushimi-machi (Osaka, Japan). RU 28318 was purchased from R\&D Systems Inc. (Minneapolis, Minn., USA), bumetanide (Ben Venue Laboratories Inc., Bedford, Ohio, USA) was purchased from Bedford Laboratories ${ }^{\mathrm{TM}}$ (Bedford, Ohio, USA), and formestane, $\beta$-estradiol and ICI 182780 were acquired from Sigma-Aldrich (St. Louis, Mo., USA).

\section{Statistical Analysis}

SigmaPlot 12.5 software (Systat Software Inc., Point Richmond, Calif., USA) was used for statistical analyses. Single comparisons were tested using the $t$ test or paired t test (slice electrophysiology data). Multiple comparisons of electroencephalographic seizure parameters among the treatment groups were analyzed using one-way ANOVA, followed by Fisher's LSD test for pairwise comparisons. Two-way repeated-measures ANOVA was used to analyze the frequency and amplitude of spikes (fig. 2d). The normality assumption test was performed using the Shapiro-Wilk test with a $\mathrm{p}$ value set at 0.05 . All comparisons were run as twotailed tests. All numerical values are expressed as the mean \pm SE. A $p \leq 0.05$ was considered significant. The sample sizes in this study were based on previous experience with the same experimental techniques $[2,13,16,17]$.

\section{Results}

Sevoflurane Causes Similar Hyperexcitation Events in Electroencephalograms of Male and Female Rat Pups

In agreement with our previous findings, anesthesia of P4-P6 rats with sevoflurane was associated with episodes of electroencephalographic seizures (fig. 2a-c). The analysis of electroencephalographic recordings revealed no statistically significant differences in sevoflurane-caused 
Fig. 2. Episodes of seizures and persistent regular spike activity in the electroencephalograms in P4-P6 rats during anesthesia with sevoflurane. a Root mean square (RMS) of the electroencephalogram of a P4 rat before and during exposure to sevoflurane. Horizontal lines mark the occurrence of episodes of electroencephalographic seizures (1) and spike electroencephalographic activity (2); the corresponding sections of the electroencephalogram are shown at an expanded time scale in $\mathbf{b}$. $\mathbf{b}$ Examples of an episode of electroencephalographic seizures (1) and electroencephalographic spike activity (2) in a $\mathrm{P} 4$ rat during exposure to sevoflurane. c Histograms showing parameters of electroencephalographic seizures during $60 \mathrm{~min}$ of exposure to sevoflurane of $\mathrm{P} 4-\mathrm{P} 6$ rats $(\mathrm{n}=21)$. d Histograms showing the frequency and amplitude of electroencephalogram spike activities in P4-P6 rats during exposure to sevoflurane. EEG spike activity during 60 min of exposure to sevoflurane was analyzed during three 5-min periods: (1) early during anesthesia (5-10 min of anesthesia); (2) in the middle of sevoflurane exposure (30-35 min of anesthesia with sevoflurane), and (3) at the end of exposure (55-60 min of exposure to sevoflurane; see illustration of the experimental protocols in fig. 1). The spike amplitude was measured as the difference between the baseline values and the peak values either in positive or negative directions.

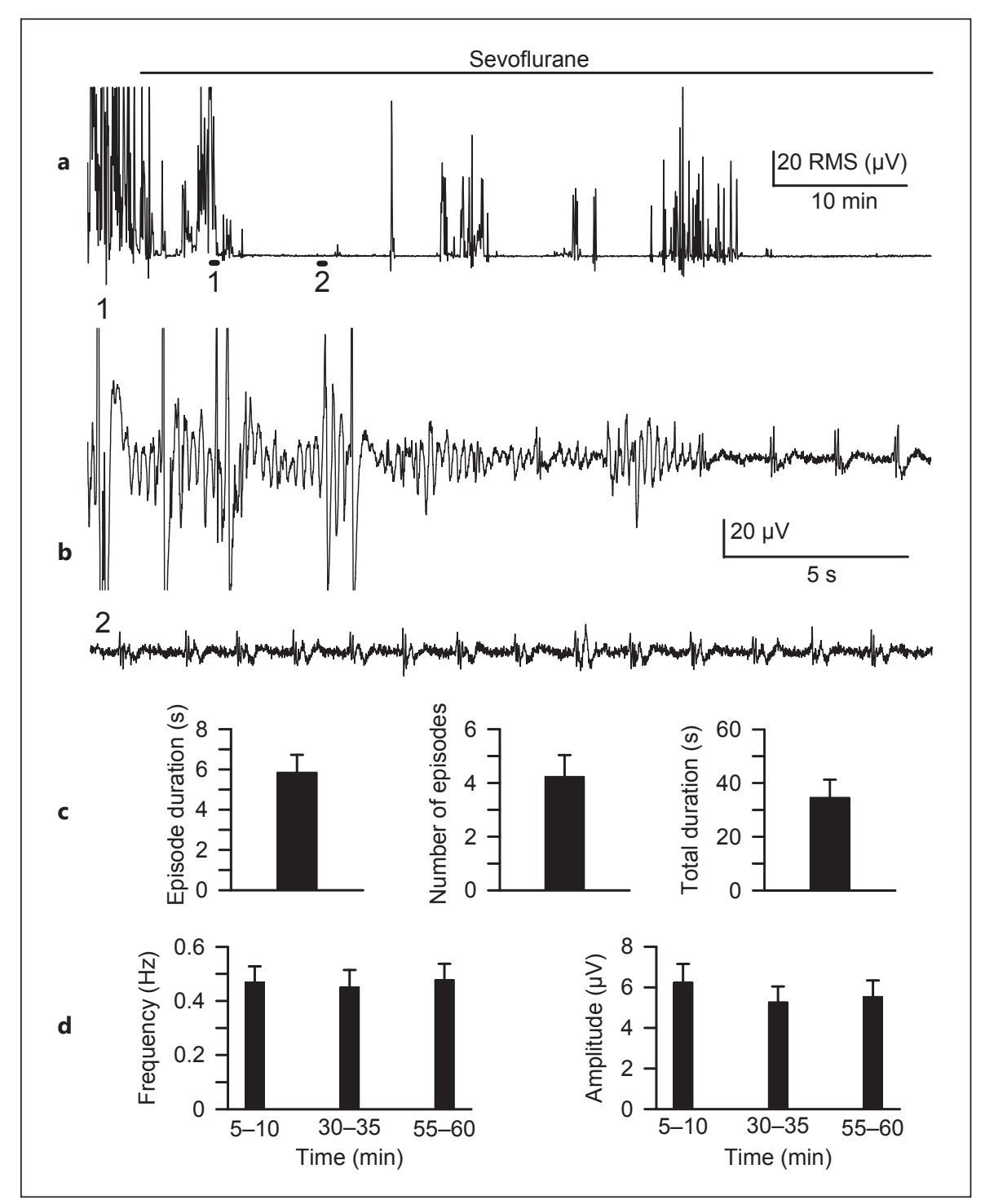

seizures between male and female rat pups, although all parameters were slightly greater for male rats. The number of episodes of electroencephalographic seizures, the duration of a single episode and the total duration of seizures during $1 \mathrm{~h}$ of anesthesia were $4.8 \pm 1.263$ and 3.727 $\pm 1.028\left(\mathrm{t}_{19}=0.664 ; \mathrm{p}=0.515\right), 6.1 \pm 1.431$ and $5.618 \pm$ $1.106 \mathrm{~s}\left(\mathrm{t}_{19}=0.269 ; \mathrm{p}=0.791\right)$, and $40.6 \pm 10.94$ and 29.09 $\pm 8.13 \mathrm{~s}\left(\mathrm{t}_{19}=0.855 ; \mathrm{p}=0.403\right)$ in male $(\mathrm{n}=10)$ and female $(\mathrm{n}=11)$ rat pups, respectively. In addition to episodes of electroencephalographic seizures, regular persistent spikes appeared in the electroencephalograms of 7 male and 8 female animals (fig. $2 \mathrm{~b}, \mathrm{~d}$ ). The spike activity in the sevoflurane-anesthetized animals frequently appeared in clusters consisting of several individual spikes. Two-way repeated-measures ANOVA of the frequency of spikes in the electroencephalograms of sevoflurane-anesthetized male and female rats sampled during three 5 -min intervals of a single anesthetic (at 5-10, 30-35 and 55-60 min of sevoflurane exposure) did not detect significant differences for gender $\left(\mathrm{F}_{1,19}=0.0334 ; \mathrm{p}=0.857\right)$ or sampling period $\left(\mathrm{F}_{2,19}=0.319 ; \mathrm{p}=0.729\right)$. The respective values for the amplitude of spikes were also similar (gender: $\mathrm{F}_{1,19}=$ $0.125 ; \mathrm{p}=0.728$; sampling period: $\mathrm{F}_{2,19}=2,962 ; \mathrm{p}=0.065$ ). Since electroencephalographic seizures and spikes and all following modulations of these activities by study agents were similar in male and female rats, all subsequent data were analyzed and presented as a combination of results obtained from male and female rat pups. 
Fig. 3. Sevoflurane-caused electroencephalographic seizures, but not spikes, were diminished by the mineralocorticoid receptor antagonist RU 28318, the estradiol receptor antagonist ICI 182780, and the estradiol synthesis inhibitor formestane. a Histograms showing parameters of electroencephalographic seizures in $\mathrm{P} 4-\mathrm{P} 6$ rats of both genders exposed to sevoflurane for $60 \mathrm{~min}$ that received as pretreatment DMSO or saline (sevoflurane group, $\mathrm{n}=$ 21), RU $28318(n=9)$, ICI $182780(n=11)$ or formestane $(n=10)$. Animals in the sevoflurane group are the same as in figure 2. ${ }^{*} \mathrm{p}<0.05$ versus the sevoflurane group. b Examples of electroencephalogram spike activity in sevoflurane-anesthetized P4-P6 rats that received RU 28318, ICI 182780 or formestane $30 \mathrm{~min}$ prior to the initiation of anesthesia with sevoflurane. c Histograms showing the frequencies of electroencephalogram spike activities in rats exposed to different treatments (the same animals as in a). The frequencies are presented as average values measured during three 5-minlong time periods of exposure to sevoflurane for 60 min: $5-10,30-35$ and $55-60$ min since initiation of anesthesia with sevoflurane. d Histograms showing serum levels of corticosterone in $\mathrm{P} 4-\mathrm{P} 6$ rats of three treatment groups: control, not exposed to sevoflurane $(n=6)$, anesthetized with sevoflurane $(\mathrm{n}=4)$ and pretreated with ICI 182780 prior to exposure to sevoflurane $(n=4)$. Rats in the sevoflurane only group received DMSO as a vehicle. Each group consisted of equal numbers of male and female rats. ${ }^{*} \mathrm{p}<0.001$ versus the control group.
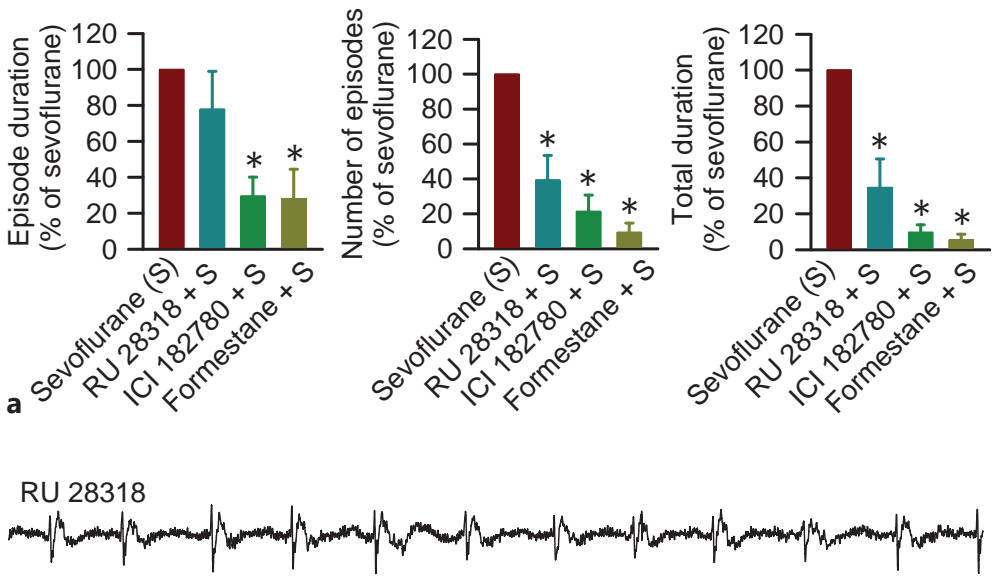

Formestane

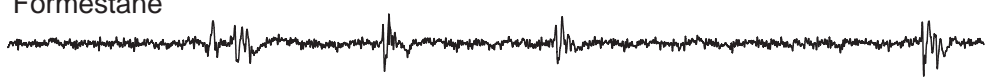

ICI 182780
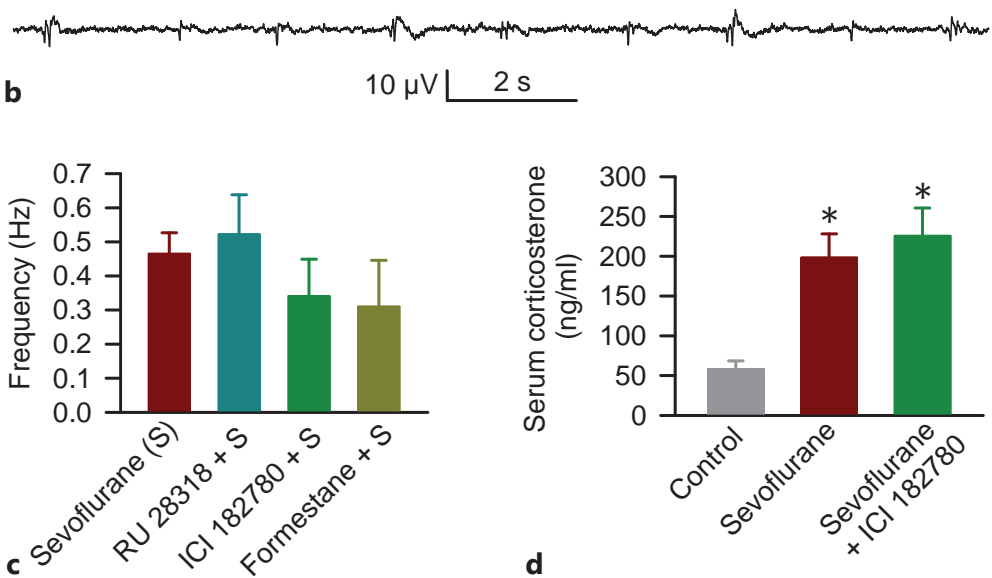

d

flurane-caused seizures ( $p=0.364$; fig. 3a). RU 28318 reduced the number of episodes to $1.667 \pm 0.601(\mathrm{p}=0.014)$ and the total duration of seizures to $12.00 \pm 5.467 \mathrm{~s}(\mathrm{p}=$ 0.008 ), respectively. The reductions of the sevofluranecaused electroencephalographic seizures caused by ICI 182780 and formestane were even more prominent (fig. 3a). The number of episodes was reduced to $0.909 \pm$ $0.392(\mathrm{p}<0.001)$ and $0.4 \pm 0.221(\mathrm{p}<0.001)$, and the total duration of seizures was shortened to $3.364 \pm 1.41 \mathrm{~s}$ ( $\mathrm{p}<$ $0.001)$ and $1.9 \pm 1.069 \mathrm{~s}(\mathrm{p}<0.001)$ in the ICI 182780- and the formestane-pretreated rats, respectively. These agents, with the exception of the mineralocorticoid receptor an- 
Fig. 4. Exogenous estradiol increased sevoflurane-caused seizures, spikes and serum levels of corticosterone. The estradiol-enhanced seizures were depressed by ICI 182780, the NKCC1 inhibitor, bumetanide and RU 28318. All these agents, except for RU 28318, diminished the estradiol-enhanced spikes. a Histograms showing parameters of electroencephalographic seizures in P4-P6 rats of both genders exposed to sevoflurane for $60 \mathrm{~min}$ that received as pretreatment DMSO or saline (sevoflurane group, $\mathrm{n}=21)$, estradiol $(\mathrm{n}=15)$, the NKCC1 inhibitor, bumetanide $(\mathrm{n}=8)$, RU $28318(\mathrm{n}=8)$ or ICI $182780(\mathrm{n}=6)$. Animals in the sevoflurane group are the same as in figures 2 and 3. b Examples of electroencephalographic seizures [estradiol (E) + sevoflurane (S)] and spikes in electroencephalograms of $\mathrm{P} 4-\mathrm{P} 6$ rats pretreated with estradiol plus bumetanide (E + bumetanide + S), estradiol plus RU 28318 (E + RU $28318+$ S) and estradiol plus ICI 182780 $(\mathrm{E}+\mathrm{ICI} 182780+\mathrm{S})$ prior to exposure to sevoflurane. c Histograms showing the frequencies of electroencephalogram spike activities in rats exposed to different treatments (the same animals as in a) prior to exposure to sevoflurane. The frequencies are presented as average values during three 5 -min-long time periods of exposure to sevoflurane for $60 \mathrm{~min}$ : 5-10, 30-35 and 55-60 min since the initiation of anesthesia with sevoflurane. d Histograms showing serum levels of corticosterone in P4-P6 rats anesthetized with sevoflurane $(\mathrm{n}=4)$ and pretreated with estradiol prior to exposure to sevoflurane $(n=5)$. Rats in the sevoflurane only group, which is the same group as in figure $3 \mathrm{~d}$, received DMSO as a vehicle. Each group consisted of equal numbers of male and female rats. a, $\mathbf{c}, \mathbf{d}^{\#} \mathrm{p}<0.05$ versus the sevoflurane group; ${ }^{*} \mathrm{p}<0.05$ versus the estradiol plus sevoflurane group.

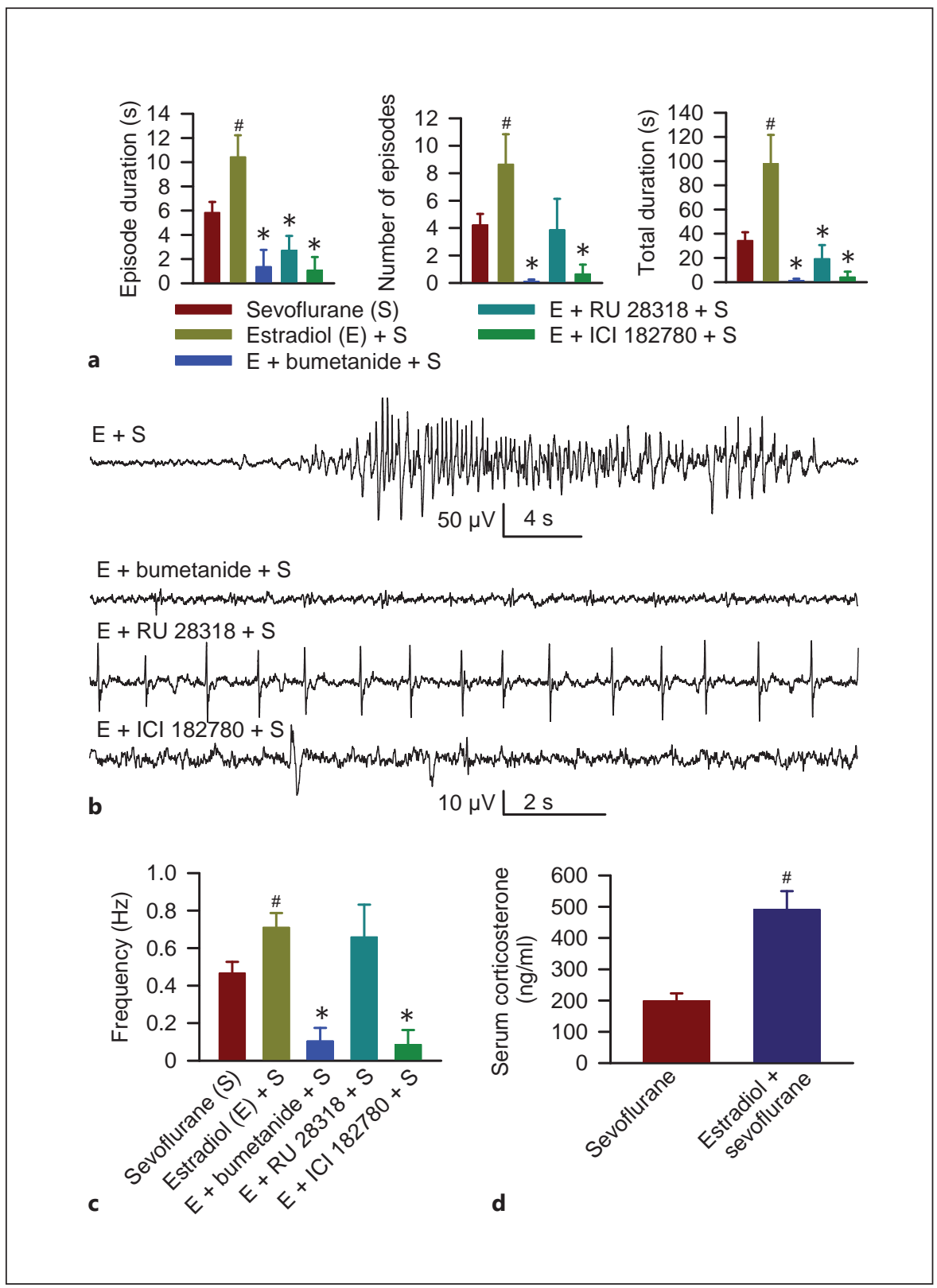

tagonist RU 28318, tended to reduce the frequency of sevoflurane-caused spikes in the electroencephalograms, but no statistical significance was achieved $\left(\mathrm{F}_{4,45}=0.878\right.$; $\mathrm{p}=0.485$; fig. $3 \mathrm{~b}, \mathrm{c}$ ).

In agreement with the depressant effects of the mineralocorticoid receptor antagonist RU 28318 on seizures caused by sevoflurane, anesthesia with sevoflurane significantly elevated the serum levels of corticosterone, an effect that was not reduced by pretreatment with the estradiol receptor antagonist ICI $182780\left(\mathrm{~F}_{2,11}=16.350\right.$; $\mathrm{p}<0.001$; fig. 3d). We were not able to detect estradiol in serum using an ELISA kit (Cayman Chemical Company).

\section{Exogenous Estradiol Potentiates Hyperexcitatory \\ Effects of Sevoflurane and Serum Levels of \\ Corticosterone}

Exogenous estradiol, administered prior to the initiation of anesthesia with sevoflurane, increased the number of episodes of seizures to $8.667 \pm 2.173\left(\mathrm{t}_{34}=-2.154 ; \mathrm{p}=\right.$ 
Fig. 5. Estradiol increased mPSCs in P4-P6 rat hippocampal CA1 neurons. a Illustration of the experimental protocol. Horizontal lines indicate time of treatment applications. b Examples of mPSC recordings from a $\mathrm{P} 5$ hippocampal CA1 neuron before the administration of estradiol (baseline activity, gray), in the presence of $1 \mu \mathrm{M}$ estradiol (dark red) and in the presence of estradiol plus $100 \mu \mathrm{M}$ picrotoxin (black). c-h Histograms showing the frequency, 10$90 \%$ rise, amplitude, area under the curve, and $90-37 \%$ decay of mPSCs before the application of estradiol (gray) and in the presence of estradiol (dark red). ${ }^{*} \mathrm{p}<0.005$ versus baseline, $\mathrm{n}=7$. e Average mPSCs during the last $3 \mathrm{~min}$ of baseline recording (gray) and in the presence of estradiol (1720 min after the start of administration of estradiol, dark red). i-I Estradiol did not affect mPSCs when it was applied in combination with the estradiol receptor antagonist, ICI $182780(1 \mu \mathrm{M})$. i Average mPSCs during the last $3 \mathrm{~min}$ of baseline recording (gray) and in the presence of estradiol (1 $\mu \mathrm{M})$ plus ICI 182780 (27-30 min period, dark pink). j-I Histograms showing the amplitude, frequency and area under the curve of mPSCs during the same periods as in $\mathbf{i}(n=3)$. Data in the figure are normalized to baseline. Pairwise statistical comparisons were done on the raw data (see text).

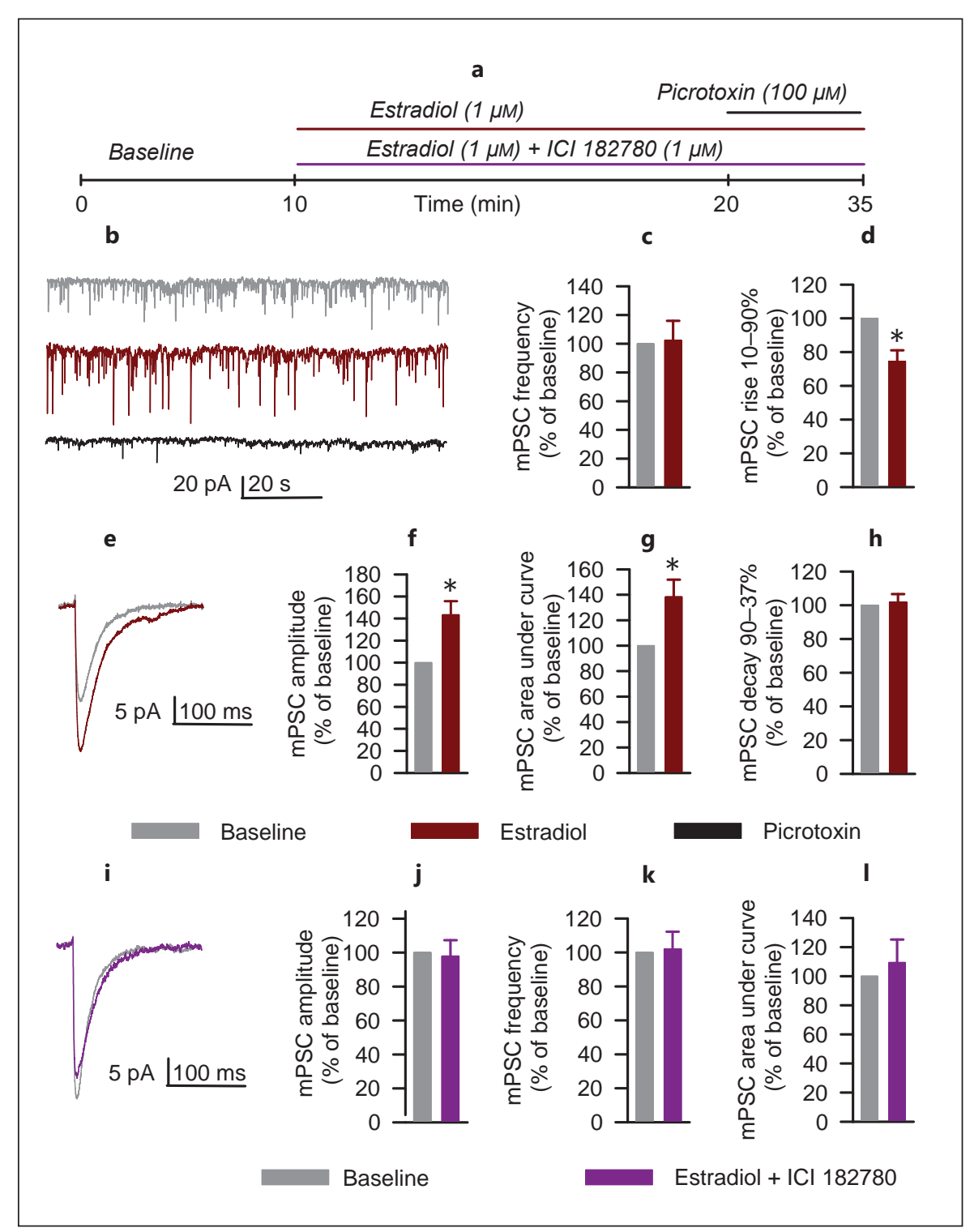

$0.0384)$, the total duration of seizures to $98.00 \pm 23.650 \mathrm{~s}$ $\left(\mathrm{t}_{34}=-2.965 ; \mathrm{p}=0.00551\right)$ and the duration of a single episode to $10.450 \pm 1.771 \mathrm{~s}\left(\mathrm{t}_{34}=-2.537 ; \mathrm{p}=0.0159\right.$; fig. $4 \mathrm{a}, \mathrm{b})$. Estradiol similarly increased the number of episodes of seizures $\left(\mathrm{t}_{13}=0.768 ; \mathrm{p}=0.457\right)$, the total duration of seizures $\left(\mathrm{t}_{13}=0.757 ; \mathrm{p}=0.463\right)$ and the duration of a single episode of seizures $\left(t_{13}=0.793 ; p=0.442\right)$ in male and female rat pups anesthetized with sevoflurane. The frequency of spikes was also increased $\left(t_{34}=-2.559\right.$; $\mathrm{p}=0.0151$; fig. $4 \mathrm{~b}, \mathrm{c})$. In contrast to animals exposed to sevoflurane only, all animals pretreated with estradiol prior to the initiation of anesthesia with sevoflurane exhibited spike activity in their electroencephalograms.
The total duration of electroencephalographic seizures, enhanced by exogenous estradiol, was diminished by ICI $182780(4.3 \pm 4.333 \mathrm{~s} ; \mathrm{p}=0.002)$ and RU $28318(19.5 \pm$ $11.087 \mathrm{~s} ; \mathrm{p}=0.004)$, and was almost completely eliminated by the NKCC1 inhibitor bumetanide $(1.4 \pm 1.375 \mathrm{~s}$; $\mathrm{p}<$ 0.001; fig. 4a). Likewise, ICI 182780 and bumetanide, but not RU 28318, significantly depressed the frequency of spike activity enhanced by estradiol in sevoflurane-anesthetized animals $\left(\mathrm{F}_{3,35}=10.309 ; \mathrm{p}<0.001\right.$; fig. $\left.4 \mathrm{~b}, \mathrm{c}\right)$.

In agreement with the increase in seizure-like EEG activity by exogenous estradiol in sevoflurane-anesthetized animals and the depressant effect of the mineralocorticoid receptor antagonist RU 28318 on these estradiol-en- 


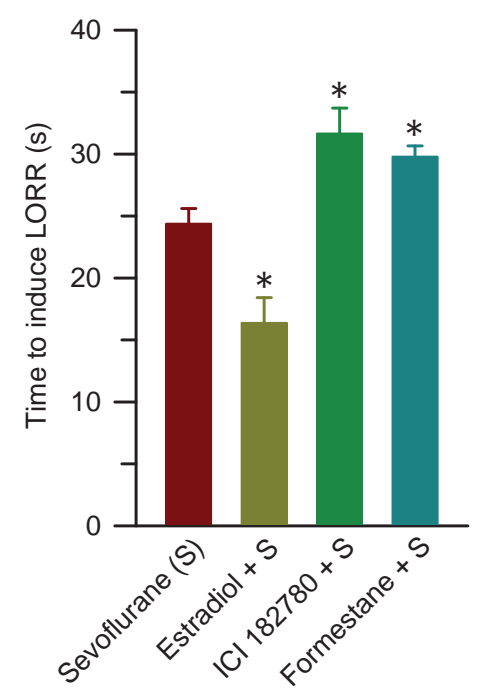

Fig. 6. Estradiol shortens and ICI 182780 and formestane lengthen the time needed for sevoflurane to induce LORR in P4-P6 rats. Histogram showing the time to LORR caused by sevoflurane (3.5\%) in P4-P6 rats that received DMSO (sevoflurane group, $\mathrm{n}=$ $5)$, estradiol $(n=5)$, ICI $182780(n=6)$ or formestane $(n=5) 30$ min before a rat pup was placed in a thermostated chamber filled with $3.5 \%$ sevoflurane. ${ }^{*} \mathrm{p}<0.05$ versus the sevoflurane group.

hanced seizures, exogenous estradiol further increased serum levels of corticosterone $\left(t_{7}=2.814 ; p=0.026\right.$; fig. $4 \mathrm{~d}$ ), the predominant agonist for mineralocorticoid receptors in the central nervous system.

\section{Estradiol Enhances $G A B A_{A} R$-Mediated Synaptic \\ Responses in Hippocampal CA1 Neurons}

mPSCs were recorded from hippocampal CA1 neurons in freshly prepared $\mathrm{P} 4-\mathrm{P} 6$ rat brain slices superfused with aCSF containing antagonists of glutamate AMPA/kainate and NMDA receptors. Estradiol was added to the superfusing aCSF after establishing baseline activity for $10 \mathrm{~min}$ (fig. 5a). The whole-cell recordings of mPSCs revealed that estradiol enhanced mPSC activity (fig. 5a-h), an effect that required more than $10 \mathrm{~min}$ to develop. For comparison, the $\mathrm{GABA}_{\mathrm{A}} \mathrm{R}$ antagonist picrotoxin, added to aCSF at the end of the experiment, almost completely depressed the mPSC activity 2-3 min after the start of its application (fig. 5b). Picrotoxin blocked the estradiol-enhanced mPSCs in all cells studied, suggesting that estradiol enhanced $\mathrm{GABA}_{\mathrm{A}} \mathrm{R}$-mediated mPSCs. A comparison of the

Exogenous Estradiol Shortens while ICI 182780 and

Formestane Lengthen the Latency to LORR Induced by Sevoflurane

Most of the cortical hyperexcitatory effects of endogenous and exogenous estradiol observed in this study are consistent with its action through the modulation of GABAergic transmission. If estradiol is involved in the mediation of the effects of sevoflurane by enhancing $\mathrm{GABA}_{\mathrm{A}} \mathrm{R}$ activity, then it should enhance the inhibitory effects of sevoflurane in neonatal rats, mediated by caudal neuronal circuitries in which $\mathrm{GABA}_{\mathrm{A}} \mathrm{R}$ signaling has already matured from excitatory to inhibitory. For this purpose, the effects of exogenous estradiol, the antagonist of estrogen receptor ICI 182780 and the inhibitor of estradiol synthesis formestane were tested on the latency of sevoflurane to induce LORR, which is predominantly mediated by midbrain neuronal networks. We found that estradiol reduced, and ICI 182780 and formestane increased the time needed for sevoflurane to induce LORR $\left(\mathrm{F}_{3,17}=16.693 ; \mathrm{p}<0.001\right.$; fig. 6$)$.

\section{Discussion}

The results of this study demonstrate that sevoflurane increases serum levels of corticosterone and causes electroencephalographic seizures and spikes that are depressed by corticosterone and estrogen receptor antagonists, by an inhibitor of estrogen synthesis, and are facilitated by exogenous estradiol. These findings suggest an involvement of steroids in the mediation of the hyperexcitatory cortical effects of sevoflurane in neonatal rats. Furthermore, the results of this study provide evidence for the involvement of endogenous estradiol in the induction of general anesthesia by sevoflurane in neonatal rats by participating in sevoflurane-induced LORR. 
In addition to the previously reported depression of electroencephalographic seizures by bumetanide $[13,16$, 17], an agent that shifts $\mathrm{GABA}_{\mathrm{A}} \mathrm{R}$-mediated signaling in immature neurons from excitatory to inhibitory $[18,19]$, the current findings indicate that sevoflurane-caused seizures could also be diminished by mineralocorticoid and estradiol receptor antagonists and an inhibitor of estradiol synthesis. Exogenous estradiol increased sevoflurane-caused seizures, an effect that was reduced by the same treatments that led to the depression of electroencephalographic seizures caused by sevoflurane alone. These findings suggest an important role of steroids, in general, and estradiol, in particular, in the developmental hyperexcitation effects caused by sevoflurane in neonatal rats. In agreement with this role, estradiol is known to exert profound and diverse effects on the developing brain $[20,21]$. Estradiol is at its highest levels during the perinatal period, and it is measured at the same levels in the male and female neonatal rat cortex $[5,6]$, supporting that similar potencies of sevoflurane cause cortical hyperexcitation in male and female pups found in this study.

The depressant effects of bumetanide on sevofluranecaused seizures $[13,16,17]$ and estradiol-facilitated sevoflurane-caused seizures point to a role of $\mathrm{GABA}_{\mathrm{A}} \mathrm{R}$-mediated excitation in these reported effects of sevoflurane and estradiol. This possibility is further supported by our finding that the acute application of estradiol to rat hippocampal slices in vitro resulted in increased $\mathrm{GABA}_{\mathrm{A}} \mathrm{R}$ mediated responses. Known effects of estradiol on GA$\mathrm{BA}_{\mathrm{A}} \mathrm{R}$-mediated signaling include an estradiol-mediated increase in the concentration of GABA-synthesizing enzymes and $\mathrm{GABA}_{\mathrm{A}} \mathrm{R}$ proteins in the olfactory bulb of the male rats [8], as well as in the hippocampal activity of $\mathrm{GABA}_{\mathrm{A}} \mathrm{R}$ in P7-P13 rats [9]. Furthermore, estradiol may enhance $\mathrm{GABA}_{\mathrm{A}} \mathrm{R}$-mediated depolarization by upregulating NKCC1 transporter activity in neonatal hypothalamic neurons [10]. Estradiol-caused elevation of intracellular calcium in immature neurons through enhancement of the depolarizing action of GABA is thought to be a primary reason why in neonatal rats estradiol exacerbates hippocampal cell damage in the presence of a GA$\mathrm{BA}_{\mathrm{A}} \mathrm{R}$ agonist [22]. A role for GABAergic mechanisms in the action of estradiol is also supported by our findings that exogenous estradiol shortened and the estrogen receptor antagonist and inhibitor of synthesis of estradiol lengthened the time needed for sevoflurane to induce LORR. The righting reflex is predominantly mediated by neuronal circuits in the midbrain $[14,15]$. In the P4-P6 rats, $\mathrm{GABA}_{\mathrm{A}} \mathrm{R}$-mediated signaling is predominantly excitatory in rostral regions such as cortical and hippocam-

Estradiol in Developmental and

Anesthetic Effects of Sevoflurane pal neurons but becomes increasingly inhibitory in more caudal regions $[18,19]$. The estradiol-, ICI 182780-, and formestane-altered times needed for sevoflurane to cause LORR support that estradiol may act not only through upregulation of NKCC1 activity, but also through enhancement of neuronal inhibition, likely by increasing GABAergic activity.

Sevoflurane and exogenous estradiol increased serum levels of corticosterone, while the electroencephalographic seizures caused by these agents were depressed by the corticosteroid receptor antagonist, RU 28318, indicating that corticosterone may be involved in the mediation of the electroencephalographic seizures, as we previously demonstrated for propofol-caused seizures in neonatal rats [2]. The known ability of corticosterone to potentiate excitatory glutamatergic activity $[23,24]$ provides a mechanistic basis for corticosterone involvement in electroencephalographic seizures caused by sevoflurane or propofol [2] in neonatal rats. It is plausible that the production and release of corticosterone that contributes to the electroencephalographic effects of sevoflurane is stimulated by sevoflurane alone, and not facilitated by physiological levels of estradiol, since the estradiol receptor antagonist ICI 182780 did not decrease the rise in serum levels of corticosterone caused by sevoflurane. This suggests that the main effect of endogenous estradiol during anesthesia with sevoflurane is mediated through enhancement of GABAergic activity.

Previously, Wójtowicz et al. [9] reported that longterm treatment with exogenous estradiol was needed to induce an increase in the amplitude and frequency of mPSCs and the amplitude of GABAergic tonic current in CA1 pyramidal cells of $\mathrm{P} 7-\mathrm{P} 13$ rats, while estradiol did not affect $\mathrm{GABA}_{\mathrm{A}} \mathrm{R}$-mediated currents in rats older than $\mathrm{P} 22$. Also, up to $24 \mathrm{~h}$ were required to detect an increase in the NKCC1 activity in hypothalamic neurons after the administration of estradiol to $\mathrm{P} 0$ rats [25]. We observed increases in $\mathrm{GABA}_{\mathrm{A}} \mathrm{R}$-mediated mPSCs in hippocampal CA1 pyramidal cells of P4-P6 rats within 10-20 min of estradiol applications. These effects of estradiol in brain slices are in agreement with our in vivo findings demonstrating that the electroencephalographic effects of estradiol, the antagonist of its receptors and the inhibitor of its synthesis can be detected within 30 min after their administration, the time when anesthesia with sevoflurane was initiated. The time frame of the effects of estradiol observed in this study is consistent with rapid estrogenic neuronal effects that could also be linked to the regulation of behavior and cognition [26, 27]. These effects may occur within seconds to minutes, but generally within $1 \mathrm{~h}$, 
and can subsequently regulate nuclear events [28]. It has been discussed that estrogens underlying these rapid actions are primarily synthesized de novo in the brain [29], and brain levels of estradiol are higher than those in the circulation [30]. This may be one plausible explanation why we were not able to detect an increase in serum levels of estradiol in neonatal rats anesthetized with sevoflurane, an important limitation of the current study. To test the possibility whether brain-produced estradiol is involved in mediating the effects of sevoflurane, we have been working to develop an assay to measure neurosteroid and estradiol levels in the neonatal rat brain using the liquid chromatography-mass spectrometry technique.

$\mathrm{GABA}_{\mathrm{A}} \mathrm{R}$-mediated depolarization, but not activation of corticosteroid receptors, is likely responsible for the persistent spike activity in the electroencephalograms since spike activity was depressed by bumetanide and further enhanced by exogenous estradiol, but was insensitive to pretreatment with RU 28318. We previously reported that RU 28318 did not affect spike activity caused by propofol [2]. Weak effects of the estrogen receptor antagonist and inhibitor of estradiol synthesis on spike activity in animals anesthetized with sevoflurane suggest that direct GABAergic effects of sevoflurane may be sufficient to support this spike activity. Electroencephalographic sei- zures and persistent spike activity suggest an increase in the excitation/inhibition ratio in neonatal rats over the entire period of exposure to sevoflurane.

In summary, the results of this study, in combination with previously published data, demonstrate important roles of steroids, particularly estradiol, in the central nervous system effects of sevoflurane in neonatal rats. Estradiol may be involved in both developmental hyperexcitatory effects of sevoflurane and in sevoflurane's inhibitory LORR effect.

\section{Acknowledgments}

We would like to acknowledge the technical contribution of Sijie Tan, postdoctoral associate, Department of Anesthesiology, University of Florida College of Medicine, Gainesville, Fla., USA; Mark Julian, medical student, William Carey University College of Osteopathic Medicine, Hattiesburg, Miss., USA, and Matthew Grove, medical student, Florida State University College of Medicine, Tallahassee, Fla., USA, and we thank Dr. Terrie Vasilopoulos, Assistant Professor, University of Florida, for her help with the statistical analysis. This study was supported by grant No. R01 GM93036-01A1 from the National Institute of Health/National Institute of General Medical Sciences, Bethesda, Md., USA (to A.E.M.), and the Jerome H. Modell, MD, FAHA Endowed Professorship, Gainesville, Fla., USA (to N.G.).

\section{References}

-1 Tan S, Xu C, Zhu W, Willis J, Seubert CN, Gravenstein N, Sumners C, Martynyuk AE: Endocrine and neurobehavioral abnormalities induced by propofol administered to neonatal rats. Anesthesiology 2014;121:1010-1017.

-2 Willis J, Zhu W, Tan S, Xu C, Perez-Downes J, Seubert CN, Gravenstein N, Martynyuk AE: Propofol-induced electroencephalographic seizures in neonatal rats: the role of corticosteroids and GABA-A receptor mediated excitation. Anesth Analg 2015;120:433-439.

3 Rothstein S, Simkins T, Nuñez JL: Response to neonatal anesthesia: effect of sex on anatomical and behavioral outcome. Neuroscience 2008 ;152:959-969.

-4 Lee BH, Chan JT, Kraeva E, Peterson K, Sall $J W$ : Isoflurane exposure in newborn rats induces long-term cognitive dysfunction in males but not females. Neuropharmacology 2014;83:9-17.

5 Amateau SK, Alt JJ, Stamps CL, McCarthy MM: Brain estradiol content in newborn rats: sex differences, regional heterogeneity, and possible de novo synthesis by the female telencephalon. Endocrinology 2004;145:29062917.
6 McCarthy MM: The two faces of estradiol: effects on the developing brain. Neuroscientist 2009;15:599-610.

7 Handa RJ, Weiser MJ: Gonadal steroid hormones and the hypothalamo-pituitary-adrenal axis. Front Neuroendocrinol 2014;35: 197-220.

8 Guerra-Araiza C, Miranda-Martinez A, NeriGómez T, Camacho-Arroyo I: Sex steroids effects on the content of GAD, TH, GABA(A), and glutamate receptors in the olfactory bulb of the male rat. Neurochem Res 2008;33: 1568-1573.

-9 Wójtowicz T, Lebida K, Mozrzymas JW: $17 \beta$-Estradiol affects GABAergic transmission in developing hippocampus. Brain Res 2008; 1241:7-17.

10 Perrot-Sinal TS, Davis AM, Gregerson KA, Kao JP, McCarthy MM: Estradiol enhances excitatory gamma-aminobutyric [corrected] acid-mediated calcium signaling in neonatal hypothalamic neurons. Endocrinology 2001; 142:2238-2243.

11 Taubøll E, Sveberg L, Svalheim S: Interactions between hormones and epilepsy. Seizure 2015;28:3-11.
12 Orliaguet G, Vivien B, Langeron O, Bouhe$\operatorname{mad}$ B, Coriat P, Riou B: Minimum alveolar concentration of volatile anesthetics in rats during postnatal maturation. Anesthesiology 2001;95:734-739.

13 Edwards DA, Shah HP, Cao W, Gravenstein $\mathrm{N}$, Seubert CN, Martynyuk AE: Bumetanide alleviates epileptogenic and neurotoxic effects of sevoflurane in neonatal rat brain. Anesthesiology 2010;112:567-575.

14 Masuda K, Yamaguchi T: Abnormal airrighting reflex in striatal rats. Jpn J Physiol 2000;50:163-166.

15 Musienko PE, Zelenin PV, Lyalka VF, Orlovsky GN, Deliagina TG: Postural performance in decerebrated rabbit. Behav Brain Res 2008;190:124-134.

16 Seubert CN, Zhu W, Pavlinec C, Gravenstein N, Martynyuk AE: Developmental effects of neonatal isoflurane and sevoflurane exposure in rats. Anesthesiology 2013;119:358-364.

17 Cao W, Pavlinec C, Gravenstein N, Seubert $\mathrm{CN}$, Martynyuk AE: Roles of aldosterone and oxytocin in abnormalities caused by sevoflurane anesthesia in neonatal rats. Anesthesiology 2012;117:791-800. 
18 Dzhala VI, Talos DM, Sdrulla DA, Brumback AC, Mathews GC, Benke TA, Delpire E, Jensen FE, Staley KJ: NKCC1 transporter facilitates seizures in the developing brain. Nat Med 2005;11:1205-1213.

19 Glykys J, Dzhala VI, Kuchibhotla KV, Feng G, Kuner T, Augustine G, Bacskai BJ, Staley KJ: Differences in cortical versus subcortical GABAergic signaling: a candidate mechanism of electroclinical uncoupling of neonatal seizures. Neuron 2009;63:657-672.

20 McCarthy MM: The two faces of estradiol: effects on the developing brain. Neuroscientist 2009; 15:599-610.

-21 Seale JV, Wood SA, Atkinson HC, Harbuz MS, Lightman SL: Postnatal masculinization alters the HPA axis phenotype in the adult female rat. J Physiol 2005;563:265-274.
22 Nuñez JL, McCarthy MM: Estradiol exacerbates hippocampal damage in a model of preterm infant brain injury. Endocrinology 2003; 144:2350-2359.

23 Karst H, Berger S, Turiault M, Tronche F, Schutz G, Joels M: Mineralocorticoid receptors are indispensable for nongenomic modulation of hippocampal glutamate transmission by corticosterone. Proc Natl Acad Sci USA 2005;102:19204-19207.

-24 Timmermans W, Xiong H, Hoogenraad CC, Krugers HJ: Stress and excitatory synapses: from health to disease. Neuroscience 2013; 248:626-636.

25 Nugent BM, Valenzuela CV, Simons TJ, McCarthy MM: Kinases SPAK and OSR are upregulated by estradiol and activate NKCC1 in the developing hypothalamus. J Neurosci 2012;32:593-598.

-26 McEwen BS, Alves SE: Estrogen actions in the central nervous system. Endocr Rev 1999;20: 279-307.
27 Srivastava DP, Waters EM, Mermelstein PG, Kramár EA, Shors TJ, Liu F: Rapid estrogen signaling in the brain: implications for the fine-tuning of neuronal circuitry. J Neurosci 2011;31:16056-16063.

28 Vasudevan N, Pfaff DW: Non-genomic actions of estrogens and their interaction with genomic actions in the brain. Front Neuroendocrinol 2008;29:238-257.

29 Srivastava DP, Penzes P: Rapid estradiol modulation of neuronal connectivity and its implications for disease. Front Endocrinol (Lausanne) 2011;2:77.

30 Ooishi Y, Kawato S, Hojo Y, Hatanaka Y, Higo S, Murakami G, Komatsuzaki Y, OgiueIkeda M, Kimoto T, Mukai H: Modulation of synaptic plasticity in the hippocampus by hippocampus-derived estrogen and androgen. J Steroid Biochem Mol Biol 2012;131:37-51. 